\title{
Fabrication and Characterization of $\mathrm{C}_{2} \mathrm{H}_{2}$ Gas Sensor Based on $\mathrm{PdO}$ doped $\mathrm{In}_{2} \mathrm{O}_{3}$ as Prepared by Flame Spray Pyrolysis
}

\author{
K.Inyawilert ${ }^{1}$, A. Wisitsoraat ${ }^{2}$, C. Liewhiran ${ }^{1}$, S. Phanichphant ${ }^{3}$, * \\ ${ }^{1}$ Department of Physics and Materials Science, Faculty of Science, Chiang Mai University, Chiang Mai \\ 50202, Thailand \\ ${ }^{2}$ Nanoelectronics and MEMS Laboratory, National Electronics and Computer Technology Center, \\ National Science and Technology Development Agency, Klong Luang, Pathumthani 12120, Thailand \\ ${ }^{3}$ Materials Science Research Center, Faculty of Science, Chiang Mai University, Chiang Mai 50202, \\ Thailand \\ sphanichphant@yahoo.com*
}

\begin{abstract}
:
0-1.0wt\% PdO doped $\ln _{2} \mathrm{O}_{3}$ nanoparticles have been successfully produced in a single step by flame spray pyrolysis (FSP) technique using indium(III) nitrate hydrate and palladium(II) acetylacetonate, as precursors dissolved in ethanol and their acetylene sensing characteristics have been investigated. The particle and sensing film properties were analyzed by XRD, BET, TEM and XPS. The sensing films were prepared by spin coating technique. The crystallite sizes of $\ln _{2} \mathrm{O}_{3}$ spherical and cubic morphologies were found to be ranging from 5 to $20 \mathrm{~nm}$ and $\mathrm{PdO}$ might form solid solution with $\mathrm{In}_{2} \mathrm{O}_{3}$ lattice. Gas-sensing characterization were studied at the operating temperatures ranging from 200 to $400^{\circ} \mathrm{C}$ in dry air, acetylene sensing characteristics of $\ln _{2} \mathrm{O}_{3}$ nanoparticles is significantly improved as $\mathrm{Pd}$ content increased from 0 to $1.0 \mathrm{wt}$.\%. The $0.75 \mathrm{wt} \% \mathrm{PdO}$ doped $\mathrm{In}_{2} \mathrm{O}_{3}$ sensing film showed an optimum $\mathrm{C}_{2} \mathrm{H}_{2}$ response of $\sim 948$ at $3 \%$ acetylene concentration and $350^{\circ} \mathrm{C}$ operating temperature. In addition, $\mathrm{PdO}$ doped $\ln _{2} \mathrm{O}_{3}$ sensing films exhibited good selectivity towards hydrogen and acetylene gas.
\end{abstract}

Key words: Flame spray pyrolysis, $\mathrm{PdO}$ doped $\mathrm{In}_{2} \mathrm{O}_{3}$, Gas sensor, $\mathrm{C}_{2} \mathrm{H}_{2}$ sensor

\section{Introduction}

Acetylene $\left(\mathrm{C}_{2} \mathrm{H}_{2}\right)$ is a colorless with a faint garlic-like odor widely used as fuel and in many industrial applications, such as a raw material for the production of experimental electrically conducting plastics, used with high purity air as a fuel for the flame in atomic absorption flame spectroscopy, used in water and biological research laboratories. It is quite unstable in pure form and usually handled in solution and becomes highly explosive when it is liquefied, compressed, heated or mixed with air. For this reason, special safety measure is vital during its production and handling. At the same time, the range of interest for its detection is much wider, typically 100-100,000 ppm, allowing for early leakage warning and explosive indication. So it's essential to detect the content of $\mathrm{C}_{2} \mathrm{H}_{2}$ to avoid more serious accidents at incipient faults. In this study the optimization of the doping conditions for $\mathrm{PdO}$ doped $\mathrm{In}_{2} \mathrm{O}_{3}$ nanoparticles are produced by flame spray pyrolysis. The effect of $\mathrm{PdO}$ on gas sensing performances are systematically studied and optimized for selective detection of $\mathrm{H}_{2}$ and $\mathrm{C}_{2} \mathrm{H}_{2}$ gas.

\section{Materials and Methods}

Firstly, $\quad 0-1.0 w t \%$ PdO doped $\ln _{2} \mathrm{O}_{3}$ nanoparticles were prepared by flame spray pyrolysis technique, which was previously established by our group. For sensor fabrication, flame-made $0-1.0 w t \%$ PdO doped $\mathrm{In}_{2} \mathrm{O}_{3}$ nanopowders were thoroughly mixed and ground with the binder solution. The resulting paste was spin coated on $\mathrm{Al}_{2} \mathrm{O}_{3}$ substrates equipped with $\mathrm{Au}$ interdigitated electrodes to form a sensing film. The resulting substrates annealed at $450^{\circ} \mathrm{C}$ for $2 \mathrm{~h}$ in an oven for binder removal prior to sensing test. The gas-sensing performances of all sensors were characterized towards $\mathrm{H}_{2}, \mathrm{C}_{2} \mathrm{H}_{2}, \mathrm{C}_{2} \mathrm{H}_{4}, \mathrm{C}_{2} \mathrm{H}_{5} \mathrm{OH}, \mathrm{H}_{2} \mathrm{~S}$ and $\mathrm{NO}_{2}$ under atmospheric conditions by the standard flow through technique in stainless steel 
chamber at operate temperature in range of $200-400^{\circ} \mathrm{C}$.

\section{Results and discussion}

Characterizations significantly confirmed $\mathrm{Pd}^{2+}$ was formed solid solution with $\ln _{2} \mathrm{O}_{3}$ lattice ((2 2 2), ( $\left.\begin{array}{lll}4 & 0 & 0\end{array}\right)$ and $\left(\begin{array}{lll}4 & 4 & 0\end{array}\right)$ ). Fig. 1 shows BF-TEM image with corresponding SAED pattern of pure $\mathrm{In}_{2} \mathrm{O}_{3}$ and optimal $\mathrm{PdO}$ doped $\mathrm{In}_{2} \mathrm{O}_{3}$ nanoparticles. It is seen that the spherical and cubic nanoparticles with the particle size in the range of 5-20 nm. The corresponding SAED patterns display diffraction rings of polycrystalline $\ln _{2} \mathrm{O}_{3}$ nanoparticles. The observed In state can be assigned to the highest oxidation state of $\mathrm{In}^{3+}$ for $\ln _{2} \mathrm{O}_{3}$. For $\mathrm{Pd}$ element can be assigned to $\mathrm{Pd}^{2+}$ of $\mathrm{PdO}$ and $\mathrm{Pd}^{4+}$ of $\mathrm{PdO}_{2}$ consistent with some other reports on XPS study. The effect of operating temperature ranging from 200 to $400^{\circ} \mathrm{C}$ on $\mathrm{C}_{2} \mathrm{H}_{2}$ response of $\operatorname{In}_{2} \mathrm{O}_{3}$ nanoparticles with different In $\mathrm{PdO}$ doping indicated that the $0.75 \mathrm{wt} \% \mathrm{PdO}$ doped $\operatorname{In}_{2} \mathrm{O}_{3}$ sensor exhibits the highest response of $\sim 948$ to 3 vol\% $\mathrm{C}_{2} \mathrm{H}_{2}$ at high temperature of $350^{\circ} \mathrm{C}$. $\mathrm{PdO}$ doped $\mathrm{In}_{2} \mathrm{O}_{3}$ sensing films exhibited good selectivity towards hydrogen and acetylene gas.
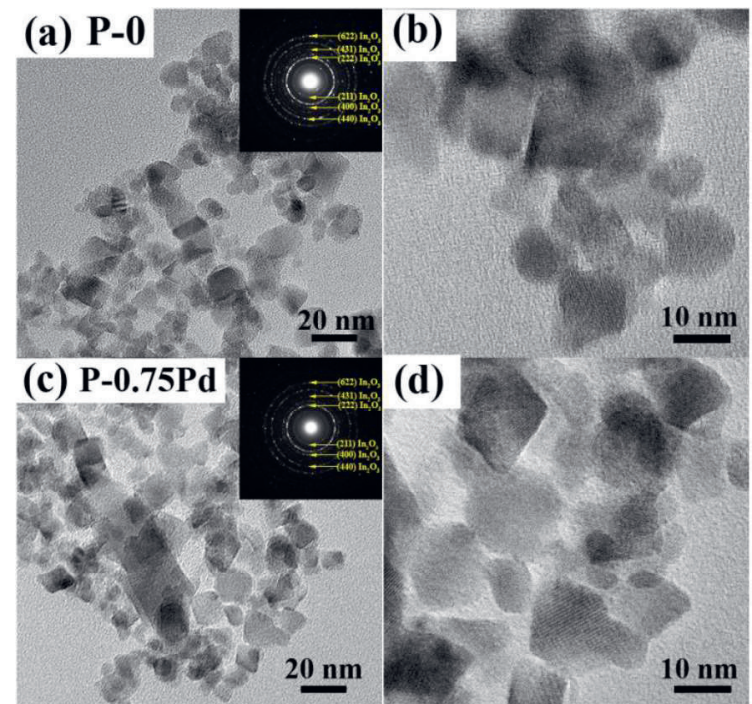

(d)

Fig.1. TEM images of the FSP-made $(a, b)$ undoped $\ln _{2} \mathrm{O}_{3}, \quad(c, \quad d) \quad 0.75 \quad w t \% \quad P d O$ doped $\ln _{2} \mathrm{O}_{3}$ nanoparticles. Insets: the corresponding SAED patterns.

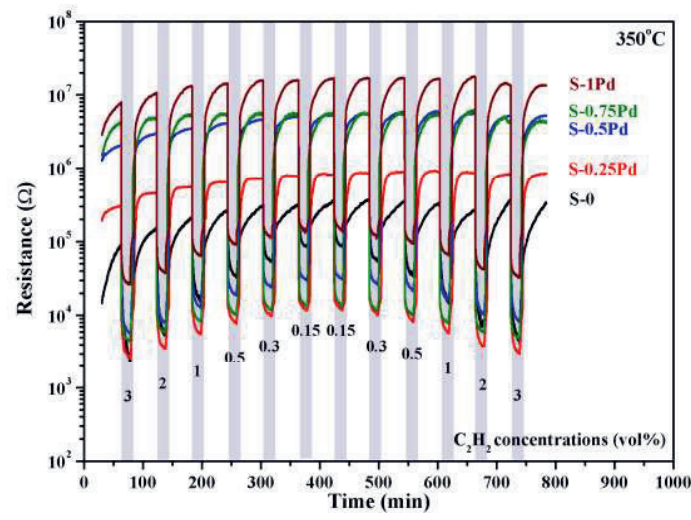

Fig.2. The change in resistance of $\operatorname{In}_{2} \mathrm{O}_{3}$ sensing films with different $\mathrm{PdO}$ doping concentrations under exposure to various $\mathrm{C}_{2} \mathrm{H}_{2}$ concentrations ranging from 0.15 to $3 \mathrm{vol} \%$ in terms of backward and forward concentrations at the operating temperature of $350^{\circ} \mathrm{C}$.

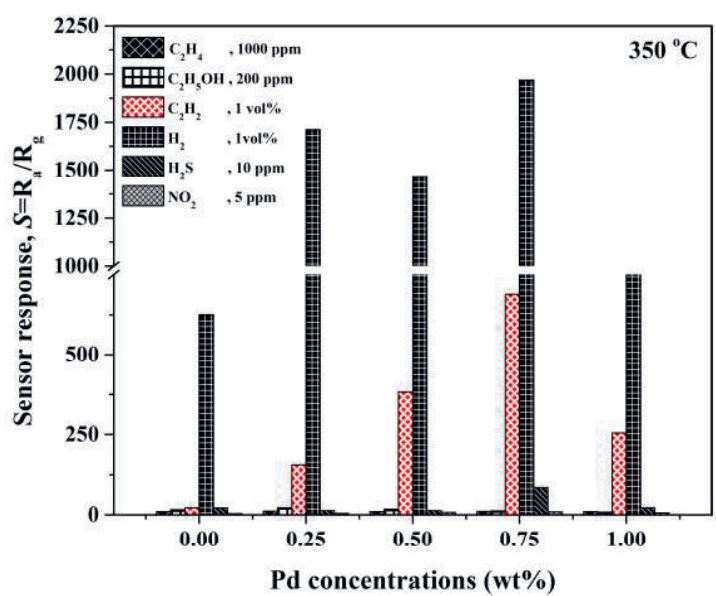

Fig. 3. Selectivity histograms: sensor response of 0 1.Owt\% PdO doped $\mathrm{In}_{2} \mathrm{O}_{3}$ sensors to $1,000 \mathrm{ppm}$ $\mathrm{C}_{2} \mathrm{H}_{4}, 2 \mathrm{OO} \mathrm{ppm} \mathrm{C}_{2} \mathrm{H}_{5} \mathrm{OH}, 1 \mathrm{vol} \% \mathrm{C}_{2} \mathrm{H}_{2}, 1$ vol\% $\mathrm{H}_{2}, 10$ ppm $\mathrm{H}_{2} \mathrm{~S}$ and $5 \mathrm{ppm} \mathrm{NO}_{2}$ at the optimal operating temperatures of $350^{\circ} \mathrm{C}$.

\section{References}

[1] N. Tamaekong, C. Liewhiran, A. Wisitsoraat, S. Phanichphant, Acetylene Sensor Based on $\mathrm{Pt} / \mathrm{ZnO}$ Thick Films as Prepared by Flame Spray Pyrolysis, Sensors and Actuators B 152, 155-161 (2011); doi: 10.1016/j.snb.2010.11.058

[2] A.S.M. Iftekhar Uddin, G.S. Chung, Fabrication and Characterization of $\mathrm{C}_{2} \mathrm{H}_{2}$ Gas Sensor Based on Ag Loaded Vertical ZnO Nanowires Array, Procedia Engineering 120, 582-585 (2015); doi: 10.1016/j.proeng.2015.08.730

[3] L. Liu, T. Zhang, S. Li, L. Wang, Y. Tian, Preparation, Characterization and Gas-sensing Properties of Pd-doped In2O3 Nanofibers, Materials Letters 63, 1975-1977 (2009); doi:10.1016/j.matlet.2009.05.060 